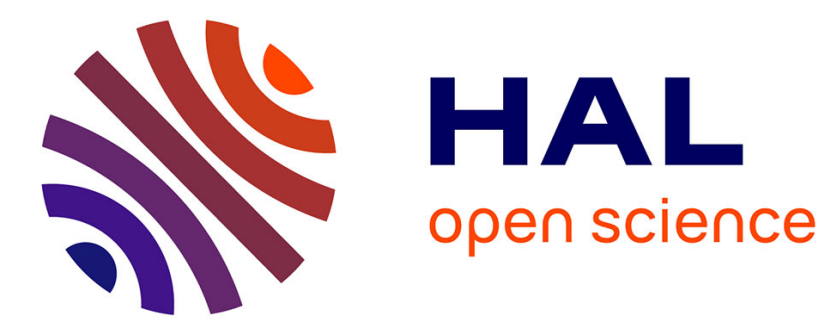

\title{
TURBULENT PLASMA IN THE FIELD OF INTENSE HIGH FREQUENCY RADIATION
}

\author{
V. Kovalev, V. Pustovalov, A. Romanov, Vivien Stefan
}

\section{To cite this version:}

V. Kovalev, V. Pustovalov, A. Romanov, Vivien Stefan. TURBUlENT PLASMA IN THE FIELD OF INTENSE HIGH FREQUENCY RADIATION. Journal de Physique Colloques, 1979, 40 (C7), pp.C7-609-C7-610. 10.1051/jphyscol:19797295 . jpa-00219284

\section{HAL Id: jpa-00219284 https://hal.science/jpa-00219284}

Submitted on 1 Jan 1979

HAL is a multi-disciplinary open access archive for the deposit and dissemination of scientific research documents, whether they are published or not. The documents may come from teaching and research institutions in France or abroad, or from public or private research centers.
L'archive ouverte pluridisciplinaire HAL, est destinée au dépôt et à la diffusion de documents scientifiques de niveau recherche, publiés ou non, émanant des établissements d'enseignement et de recherche français ou étrangers, des laboratoires publics ou privés. 


\section{TURBULENT PLASMA IN THE FIELD OF INTENSE HIGH FREQUENCY RADIATION}

V.F. Kovalev, V.V. Pustovalov, A.B. Romanov and V. Stefan*.

P.N. Lebedev Bhysical Institute of Academy of Sciences of the U.S.S.R., Moscow, U.S.S.R. Boris Kidric Institute of Nuclear Seiences, Beograd Yugoslavia.

In present-day experimints dealing with the interaction of strong electromagnetic radiation vith plasma high energy fluxes of the incident radiation are in use. For example, in the optical domain of frequencies the energy flux reaches the value of $10^{16}$ $10^{17} \mathrm{~W} / \mathrm{cm}^{2} / 1 /$. Along with this, situations when strong radiation propagates through the plasma with high level of turbulent noise are very often encountered (plasma focus $/ 2,3 /$ or ionospheric plasma /4/). In the presence of the pump field turbulent plasma spectrum is affected in such a way that "failures" appear in the longwave domain when the wavelenth is of the order of electron oscilation amplitude in the external field.

For the desciption of the homogeneous isotropic plasma interacting with the external radiation $E_{0}(t)=E_{0}$ sin $\omega_{0} t$ with the frequency $\omega_{0}$ much higher than the electron Langmuir frequency $\omega_{L e}$ ' Vlasov kinetic equation, in the form of the hydrodynamical system $/ 5 /$, is used, onthe base of which a nonlinear dispersion relation for the correlation function $\psi=\left\langle\Psi_{i} \psi_{i}^{*}\right\rangle=\frac{k^{2}}{2 \pi}|\rho|^{2}$ can be obtained

$\Psi(k) \varepsilon_{0}(k)-\frac{2}{\varepsilon_{0}\left(-k^{2}\right)} \int d k^{\prime} d k^{\prime \prime} \delta\left(k-k^{\prime}-k^{\prime \prime}\right) \Psi\left(k^{\prime}\right) \Psi\left(k^{\prime \prime}\right) \times$

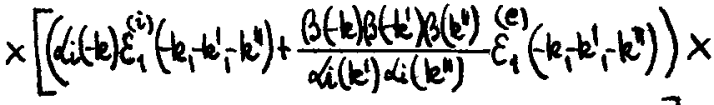

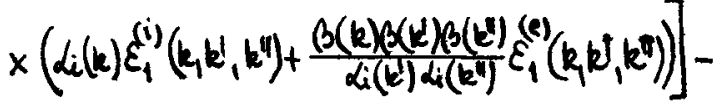
$-\Psi(k) \int d k^{\prime} d k^{\prime} \delta\left(k-k^{\prime}-k^{\prime \prime}\right)\left\{\frac{4}{\varepsilon_{0}\left(k^{\prime \prime}\right)}\left[k_{i}(k) \varepsilon_{1}^{(i)}\left(k, k_{1}^{\prime}, k^{\prime \prime}\right) \times\right.\right.$ $\left(\alpha_{i}\left(k^{\prime}\right) \varepsilon_{1}^{(i)}\left(k_{1}^{\prime \prime}-k_{1}^{\prime}, k\right)+\frac{\beta(k) \beta\left(k^{\prime}\right) \beta\left(k^{\prime \prime}\right)}{\alpha_{i}(k) \alpha_{i}\left(k^{\prime}\right)} \varepsilon_{1}^{(e)}\left(k_{1}^{\prime \prime}-k_{1}^{\prime}, k\right)\right)+\beta(k) \varepsilon_{1}^{(e)}\left(k_{1}\right) \varepsilon_{1} \theta_{x}$ $x\left(\alpha_{e}\left(k^{\prime}\right) \varepsilon_{1}^{(e)}\left(k_{1}^{\prime \prime}-k_{1}^{\prime}, k\right) \frac{\beta(k) \beta^{2}\left(k^{\prime}\right)}{\alpha_{i}\left(k^{\prime}\right) \alpha_{i}^{2}\left(k^{\prime}\right)}+\frac{\beta\left(k^{\prime \prime}\right) \beta\left(k^{\prime}\right)(i)}{\alpha_{i}\left(k^{\prime}\right)} \varepsilon_{1}\left(k_{1}^{\prime \prime}-k^{\prime} k\right)\right]$ $-3 \alpha \alpha_{i}(k)\left[\varepsilon_{2}^{(i)}\left(k_{1} k_{1}^{\prime}, k_{1}-k^{\prime}\right)+\frac{B^{2}(k) \beta^{2}\left(k^{\prime}\right)}{\alpha_{i}^{2}(k) \alpha_{i}^{2}\left(k^{\prime}\right)} \varepsilon_{2}^{(e)}\left(k_{1} k^{\prime}, k_{1}, k^{\prime}\right)\right] \psi \psi\left(k^{\prime}\right)=0$ $\alpha_{e}(k)=1+\sqrt{\varepsilon_{i}}(k)\left(1-J_{0}^{2}(a)\right) \alpha_{i}(k)=1+\delta \varepsilon_{e}(k)\left(1-J_{0}^{2}(a)\right), \beta(k)=J_{0}(a)$ $\varepsilon_{0}(k)=1+\delta \varepsilon_{e}(k)+\delta \varepsilon_{i}(k)+\delta \varepsilon_{e}(k) d \varepsilon_{i}(k)\left(t J_{0}^{2}(k)\right), \pm k=(t \vec{k}+w)$ Here $J_{0}(x)$ is Bessel function, $\delta \varepsilon_{\alpha}(\omega, \vec{k}$ partial plasma polarizability of " $\alpha$ " plasma component and $\varepsilon_{1}^{(\alpha)}$ and $\varepsilon_{2}^{(\alpha)}$ first and second nonlinear dielectric permeability of " $\alpha$ " plasma component.

In equation (1) the first addendum includes the effect of high-frequency field $E_{0}(t)$ on plasma dielectric permeability $\varepsilon_{0}(k) / 6,7 /$ the change of nonlinear interaction of plasma waves in the presence of the high-frequeney field is included in remaining addends.

Let us consider now the process of induced scattering of the Langmuir waves on particles in the external field $E_{o}(t)$ when

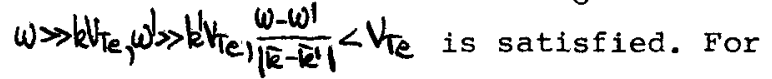
the spectral density of oscillation energy $N(k)$ the following equation is obtained

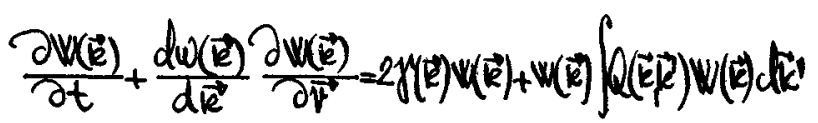

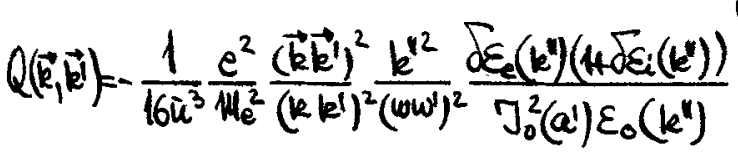
In a magnetized plasma, the turbulence of the oblique Langmuir waves, excited, for example, by encountering electron beams 
with velocities $\pm \vec{u}_{b}$, paralel to magnetic field $\vec{B}_{0}$ is characterized by stationary spectral distribution /4/ which in a strong high-frequency field $a=\left(\vec{k} \vec{k}_{e}\right)>1$ appeared to be modulated over the frequency with the period Tum $\omega_{0}^{2} \mu_{b} / e E_{0}$

$W(\vec{k}) \sim \tilde{S}((\cos \theta))]_{0}^{2}\left(\frac{e E_{0}}{m \omega_{0}^{2}} \frac{\omega_{l}}{\omega_{b}}|\cos \theta|\right) \delta\left(k-\frac{\omega_{L}}{\omega_{b}}\right), \vec{E}_{0} \| \overrightarrow{B_{0}}$

$$
\cos \theta=\vec{k} \vec{B}_{0} / k B_{0}
$$

Here $\tilde{S}(|\cos \theta|)$ describes angle distributions of plasma turbulent noise in the presence of the external field $\vec{E}_{0}(t)$. The characteristic modulation of the spectral distribution $\left(\sim_{0}^{2}(a)\right)$ connected with the effective amplification of nonlinear interaction of waves in a strong high frequency field, apnears in the form of kernel modification $\left(Q(\vec{k}, \vec{k}) \sim \nabla_{0}^{-2}\left(a^{\prime}\right)\right)$.

Spectral distribution (3) also describes the modulation of the plasma noise in the case when instabilities arise because of the presence of electron beams in the current-carrying plasma with velocity $u_{b}$ (velocity of a beam is oriented along drift velocity $\vec{u}, \quad\left(\vec{u} \vec{u}_{b}\right)>0$. The angle distribution of plasma noise in that case, certain$1 y$, has other form $/ 8 /$. Let us note that modulation of plasma noise by high-frequency external field appears if intensity of external field is strong enough $E_{0} \sim \frac{m_{0} \omega_{0}^{2}}{e k}$ So, in the above case of current carrying plasma with electron beam defined by parameters $n_{e}=10^{18} \mathrm{~cm}^{-3}, n_{b} / n_{e}=10^{-3}, u_{b}=4,2 \cdot 10^{9}$ $\mathrm{cm} / \mathrm{s}, \mathrm{u}=4 \cdot 10^{7} \mathrm{~cm} / \mathrm{s}, \mathrm{T}_{\mathrm{e}}=\mathrm{T}_{i}=\mathrm{T}_{\mathrm{b}}=100 \mathrm{keV}$ charac teristical for plasma focus, oscilations with wave number with wave number $k \sim 210^{4} \mathrm{~cm}^{-1}$ could be excited. Here $n_{b}$ - particle density of beam electrons, $n_{e}$ - particle density of current carrying plasma electrons, $T_{e, i}$ temperature of electrons (ions) of current carrying plasma and $\mathrm{T}_{\mathrm{b}}$ temperature of beam electrons. In the case of using $\mathrm{CO}_{2}$ laser as source of high-frequency field, necessary value of energy flux is $q \sim 4 \cdot 10^{14} \mathrm{~W} / \mathrm{cm}^{2}$, obtainable in present time devices.

REFERENCES

$/ 1 /$ W.L.Kruer, et al, collective behaviour in recent laser-plasma experiments, Lawren= ce Livermore Labotatory, June 7,Preprint UCRL $77730,(1976)$

/2/ V.A.Gribkov, et al, works of FIAN,85, (1976) 193,

/3/ K.Yoneyoshi, et al, J.Phys.Jap. 11 (1976) 1081

/4/ Yu.V.Golikov, et al,JETP Lett.22(1975) 3 (in russian)

/5/ V.V.Pustovalov, et al, Lebedev Institu te Report, No.12,(1976) 28,

/6/ Yu.M.Aliev, V.P.Silin, JETP 48(1965) 901

/7/ V.I.Domrin, Preprint FIAN USSR, No.38, (1967)

/8/ V.V.Pustovalov, et al, Preprint FIAN USSR, No.183, (1973) 